\title{
The pituitary-ovarian complex in the aged anoestrous golden hamster
}

\author{
T. A. Parkening, T. J. Collins, I. F. Lau*† and S. K. Saksena* \\ Department of Anatomy, University of Texas Medical Branch, Galveston, Texas 77550, U.S.A. \\ and *The Worcester Foundation for Experimental Biology, Shrewsbury, Massachusetts 01545 , \\ U.S.A.
}

\begin{abstract}
Summary. Plasma and pituitary hormones of young (3-5 months of age) dioestrous hamsters with normal cycles and aged (13-17 months of age) anoestrous hamsters were compared. The anoestrous hamsters exhibited lower plasma values of progesterone $(P<0.001)$, oestradiol-17 $\beta(P<0.005)$ and prolactin $(P<0.001)$ and higher levels of plasma gonadotrophins $(P<0.001)$ than did the dioestrous animals. Pituitary concentrations of LH were higher $(P<0.005)$ in anoestrous hamsters, but pituitary FSH and prolactin values did not differ. In another series of experiments three groups of hamsters (3-5- and 13-17-month-old with normal cycles and 13-17-month-old in anoestrus) were ovariectomized. Blood samples were taken by cardiac puncture every $3-4$ weeks after receiving s.c. injections of oestradiol- $17 \beta$ ( 1 or $10 \mu \mathrm{g} / 100 \mathrm{~g}$ body wt) for 2 or 9 consecutive days. The markedly lower levels of gonadotrophins in aged anoestrous hamsters indicated that the hypothalamic-hypophysial complex was incapable of responding to the same degree as it did in young and aged cyclic animals. Prolactin values were similarly depressed in all 3 groups. Oestradiol-17 $\beta$ treatment caused reduced gonadotrophin and increasing prolactin concentrations in all 3 groups. These results indicate that the ovaries of the senescent anoestrous hamster produce less steroids and suggest that age-related changes in the hypothalamic-hypophysial complex are largely responsible for the cessation of regular oestrous cycles.
\end{abstract}

\section{Introduction}

Age-related changes in the mammalian reproductive system are responsible for a reduction in fecundity. Several years before the menopause, the menstrual cycle of the human female has a tendency to become irregular. While laboratory rodents do not have a menstrual cycle, a characteristic feature of their ageing process is the loss of normal oestrous cycles. Vaginal smears of laboratory rats show irregularities by 9-12 months of age, followed sequentially by some animals entering periods of constant oestrus (smears of cornified epithelial cells with ovaries containing follicles) and repetitive pseudopregnancies of an irregular length (smears predominantly of leucocytes with ovaries containing corpora lutea and follicles) (Aschheim, 1961, 1976; Clemens \& Meites, 1971; Huang \& Meites, 1975; Lu, Hopper, Vargo \& Yen, 1979). Rats 2-3 years old may enter an anoestrous state (smears predominantly of leucocytes with small ovaries containing a few small follicles) (Meites, Huang \& Simpkins, 1978; Lu et al.,

† Present address: Mason Research Institute, 57 Union Street, Worcester, Massachusetts 01608, U.S.A. 
1979). Laboratory mice likewise have a tendency to become acyclic with age and more commonly exhibit prolonged periods of dioestrus rather than constant oestrous cycles (Thung, Boot \& Mühbock, 1956; Parkening, Collins \& Smith, 1980a). Unlike rats or mice, golden hamsters maintain very regular 4-day oestrous cycles which can be determined by examining the vaginal discharge. Hamsters beyond 12 months of age may suddenly become anoestrous with a daily yellowish-white, watery vaginal discharge, consisting primarily of leucocytes. This condition may or may not be preceded by a brief period of irregular oestrous cycles. When hamsters reach this stage they rarely return to any form of oestrous cycle.

Plasma concentrations of luteinizing hormone ( $\mathrm{LH})$, follicle-stimulating hormone (FSH) and prolactin vary in aged laboratory rats, depending upon the type of cyclic irregularity exhibited by the older female and upon which day of the oestrous cycle comparisons are made with younger females exhibiting normal cycles (Huang, Steger, Bruni \& Meites, 1978). In general, however, older female rats exhibit a reduced capacity to secrete LH and FSH (an exception being constant-oestrous females that secrete more FSH during morning hours) and an increased capacity to secrete prolactin when compared with younger females (Huang, Marshall \& Meites, 1976; Riegle \& Miller, 1978; Lu et al., 1979). In contrast, concentrations of LH and FSH are statistically higher and prolactin levels are significantly lower in oestrous and constantdioestrous aged $\mathrm{C} 57 \mathrm{BL} / 6$ mice when compared to those of younger oestrous mice (Parkening $e t$ al., 1980a). The present study was undertaken to determine the amounts of plasma and pituitary LH, FSH and prolactin in mature dioestrous hamsters with normal cycles and senescent anoestrous hamsters for comparison with those of the rat and mouse. The concentrations of plasma progesterone and oestradiol-17 $\beta$ were analysed from the same hamsters in an effort to correlate changing levels of these steroids with any differences occurring in the concentrations of gonadotrophins and prolactin. Ovariectomized hamsters of both age groups were also examined to detect any age-related differences in the gonadotrophin and prolactin response of the pituitary to exogenous oestradiol-17 $\beta$.

\section{Materials and Methods}

\section{Animals}

Golden hamsters (Mesocricetus auratus) were caged individually in a temperature-controlled $\left(22-24^{\circ} \mathrm{C}\right)$, artificially lit room with $14 \mathrm{~h}$ light $(06: 00-20: 00 \mathrm{~h}) / 24 \mathrm{~h}$. Animals were provided with food and water ad libitum, supplemented with fresh carrots and lettuce once a week. The young, 3-5-month-old hamsters were obtained at 2 months of age, immediately mated and allowed to litter once and wean their young before the experiment began. The aged, 13-17-month-old hamsters were purchased as retired breeders at 8 months of age and allowed to breed and raise litters until becoming anoestrous. The hamsters were purchased from Sasco, Inc., Omaha, Nebraska. All of the young hamsters used in these experiments exhibited a normal 4-day oestrous cycle and all of the older hamsters exhibited a typical daily anoestrous vaginal discharge (predominantly a leucocytic smear) for 1-2 months after the last oestrous cycle.

\section{Study 1}

In the initial study young dioestrous and aged anoestrous hamsters were lightly anaesthetized with ether and bled from the abdominal vena cava with a heparinized syringe. Immediately after blood collection the animal was killed and the pituitary was removed and weighed. The neural lobe was then removed and the pars intermedia and pars distalis divided into halves. One half was fixed in a picric acid-paraformaldehyde fixative for immunocytochemical studies, and the remaining half was reweighed and homogenized in $1.0 \mathrm{ml} 0.01$ M-phosphate buffered saline containing 0.05 M-EDTA and $0.1 \%$ sodium azide (pH 7.6). Plasma 
and pituitary homogenates were stored at $-80^{\circ} \mathrm{C}$ until all samples could be analysed in the same assay. The ovaries were dissected from surrounding mesenteries and adipose tissue, weighed, fixed in Bouin's solution and embedded in paraffin wax.

Ovaries were serially sectioned at $5 \mu \mathrm{m}$ and stained with haematoxylin and periodic acid-Schiff (PAS). Follicles were counted in every 8 th section at $\times 25$ magnification and classified according to their stage of development. Follicular development was divided into 6 stages according to the classification of Greenwald (1974). Stages 1, 2, 3 and 4 consisted of preantral follicles having 2-3, 4-5, 6-7 and 8 or more layers of granulosa cells, respectively. Stage 5 consisted of follicles in which antrum formation had begun (isolated lacunae were evident) and Stage 6 was characterized by follicles having a single prominent antrum. Only follicles which appeared histologically normal (i.e. no pycnotic granulosa cells or fragmented oocytes) were counted.

\section{Study 2}

Normally cyclic young (3-5-month-old) and aged (13-17-month-old) hamsters on the day of dioestrus or aged anoestrous hamsters were ovariectomized and allowed 3 weeks to recover. The aged cyclic hamsters were included as controls in these studies, because it is known that intact females of this group exhibit gonadotrophin and steroid levels similar to those of younger females (Parkening, Saksena \& Lau, 1978). Blood samples $(0.5-1.0 \mathrm{ml})$ were collected by cardiac puncture from unanaesthetized females and they were allowed 3 weeks to recover. The same females (19 young, 10 aged cycling and 10 aged anoestrous) were then injected s.c. with oestradiol-17 $\beta(1 \mu \mathrm{g} / 100 \mathrm{~g}$ body wt dissolved in corn oil) at 09:00 $\mathrm{h}$ on 2 consecutive days and blood was collected by cardiac puncture between 10:00 and 12:00 h on the following day. After 3 weeks the hamsters were injected with the same concentrations of oestradiol-17 $\beta$ for 9 consecutive days and bled at the same time on the following day. The same procedures were repeated on the same animals for 2 and 9 days 4 weeks later except that each animal received 10 $\mu \mathrm{g}$ oestradiol-17 $\beta / 100 \mathrm{~g}$ body weight. The plasma samples from each experiment were then analysed at the same time by radioimmunoassay to determine circulating levels of LH, FSH and prolactin.

\section{Hormone assays}

Progesterone and oestradiol-17 $\beta$. Tritiated quantities (approximately 2500 d.p.m. $/ 0 \cdot 1 \mathrm{ml}$

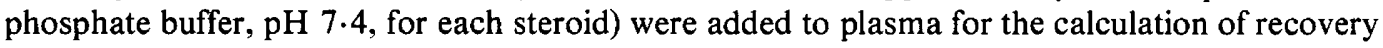
losses. Extraction was accomplished by mixing the plasma samples $(0.7-1.0 \mathrm{ml})$ with $10 \mathrm{ml}$ diethyl ether on a vortex mixer for $45 \mathrm{sec}$. Progesterone and oestradiol-17 $\beta$ were separated on microcelite columns (Saksena, Lau \& Chang, 1977) and their concentrations analysed by radioimmunoassay (Saksena et al., 1976). All comparisons were based on samples measured in a single assay. The antiserum for progesterone was obtained from Dr G. E. Abraham. The antiserum to oestradiol-17 $\beta$ (gift from Dr B. V. Caldwell) binds equally well with oestrone and after specific chromatographic separation can be used for determining levels of either of these oestrogens (Orczyk, Caldwell \& Behrman, 1974). The sensitivities of the assays were $6.25 \mathrm{pg}$ oestradiol-17 $\beta /$ tube $(0.3 \mathrm{ml})$ and $25 \mathrm{pg}$ progesterone/tube $(0.3 \mathrm{ml})$ and the intra-assay coefficients of variation were $<10 \%$ for both hormones.

LH, FSH and prolactin. Plasma and pituitary values of $\mathrm{LH}, \mathrm{FSH}$ and prolactin were measured by rat radioimmunoassay kits provided by the NIAMDD. The assay and iodination procedures were the same as those previously described (Parkening et al., 1980a, b). In agreement with other studies (Bast \& Greenwald, 1974; Bex \& Goldman, 1975) various aliquots of plasma and serial dilutions of the supernatant from pituitary homogenates of the golden hamster were found to be parallel to standard curves obtained with NIAMDD-Rat-LH-RP1, 
NIAMDD-rat-FSH-RP1 and NIAMDD-PRL-RP1, except that values for prolactin in pituitary homogenates were not statistically parallel $(P>0.05)$ with the rat standard (Parkening et al., $1980 \mathrm{~b})$. Pituitary prolactin concentrations were determined because they provided a means of comparing prolactin in the two age groups, even though the quantitative values did not represent the actual amounts of prolactin present. The antiserum used in each assay system was NIAMDD anti-rat-LH-S3, NIAMDD anti-rat-FSH-S6 or NIAMDD-anti-rat PRL-S5. Plasma and pituitary LH, FSH and prolactin levels were determined in duplicate using $100 \mu \mathrm{l}$ samples for each plasma level and 100-200 $\mu 1$ aliquots of a 1:20 dilution of the homogenate for each pituitary level. Preincubation for $24 \mathrm{~h}$ at $4^{\circ} \mathrm{C}$ of the hormone standards or plasma or pituitary samples with $200 \mu \mathrm{l}$ of the appropriate antiserum was followed by the addition of $100 \mu \mathrm{l}$ (approximately 20000 c.p.m.) of the corresponding iodinated hormone. After an additional $24 \mathrm{~h}$ of incubation, the preincubating antiserum was added and allowed to react for another $24 \mathrm{~h}$ at room temperature. The sample was then centrifuged at $2000 \mathrm{~g}$ and the pellet recovered, dissolved in $1 \mathrm{~N}-\mathrm{NaOH}$ and counted in a Packard Tricarb Spectrometer. Final working dilutions of $1: 100000$ anti-rat LH, 1:10000 anti-rat FSH and 1:25000 anti-rat prolactin resulted in the total binding of 21,19 and $31 \%$ of the iodinated hormones respectively. The hormonal levels of the unknown were expressed as ng equivalents of NIH-LH-S1, NIH-FSH-S1, or NIH-PRL-S1 per ml plasma or $\mu \mathrm{g}$ pituitary wet weight. Intra-assay coefficients of variations were $6 \cdot 5,8 \cdot 9$ and $5.7 \%$ for LH, FSH and prolactin, respectively, in Study 1 and $6 \cdot 9,9 \cdot 7$ and $6.4 \%$, respectively in Study 2. The sensitivities of the assays were $1 \mathrm{ng} \mathrm{LH} /$ tube, $10 \mathrm{ng} \mathrm{FSH} /$ tube and $0.2 \mathrm{ng}$ prolactin/tube.

\section{Analyses}

Student's $t$ test was employed for statistical purposes except for the comparison of samples for ovariectomized females for which a two-way analysis of variance (ANOVA) for a single-factor (age) completely randomized experiment with repeated measures on a second factor (oestradiol-17 $\beta$ treatment) was performed on each variable. The ANOVA for each variable provided information on three sources of variability: age, treatment and age versus treatment interaction. For this analysis only data collected sequentially throughout the experiment from young cyclic $(\mathrm{N}=12)$, aged cyclic $(\mathrm{N}=6)$ and aged anoestrous $(\mathrm{N}=5)$ females was applicable.

\section{Study 1}

\section{Results}

Aged anoestrous hamsters had a lower body weight than did the younger animals but heavier ovaries (Table 1). There were no statistically significant differences in the pituitary wet weights of the two age groups. Circulating plasma concentrations of $\mathrm{LH}$ and FSH were higher $(P<0.001)$ while concentrations of prolactin $(P<0.001)$, progesterone $(P<0.001)$ and oestradiol-17 $\beta(P<0.005)$ were considerably lower in anoestrous hamsters compared with those from younger dioestrous animals (Table 1). Pituitary concentrations of LH were also

\section{PLATE 1}

Fig. 1. Ovary of a 4-month-old normally cyclic hamster during dioestrus. Corpora lutea (CL) and various types of follicles are evident. $\times 28$.

Fig. 2. Ovary of a 16-month-old anoestrous hamster showing the lack of corpora lutea. $\times 28$.

Fig. 3. Ovary of a 4-month-old dioestrous normally cyclic hamster. The ovary contains numerous follicles. $\times 45$.

Fig. 4. Ovary of a 14-month-old anoestrous hamster showing numerous follicles but none at the mature antral stage. The previous oestrous cycle had been $>1$ month earlier. $\times 45$. 
PLATE 1
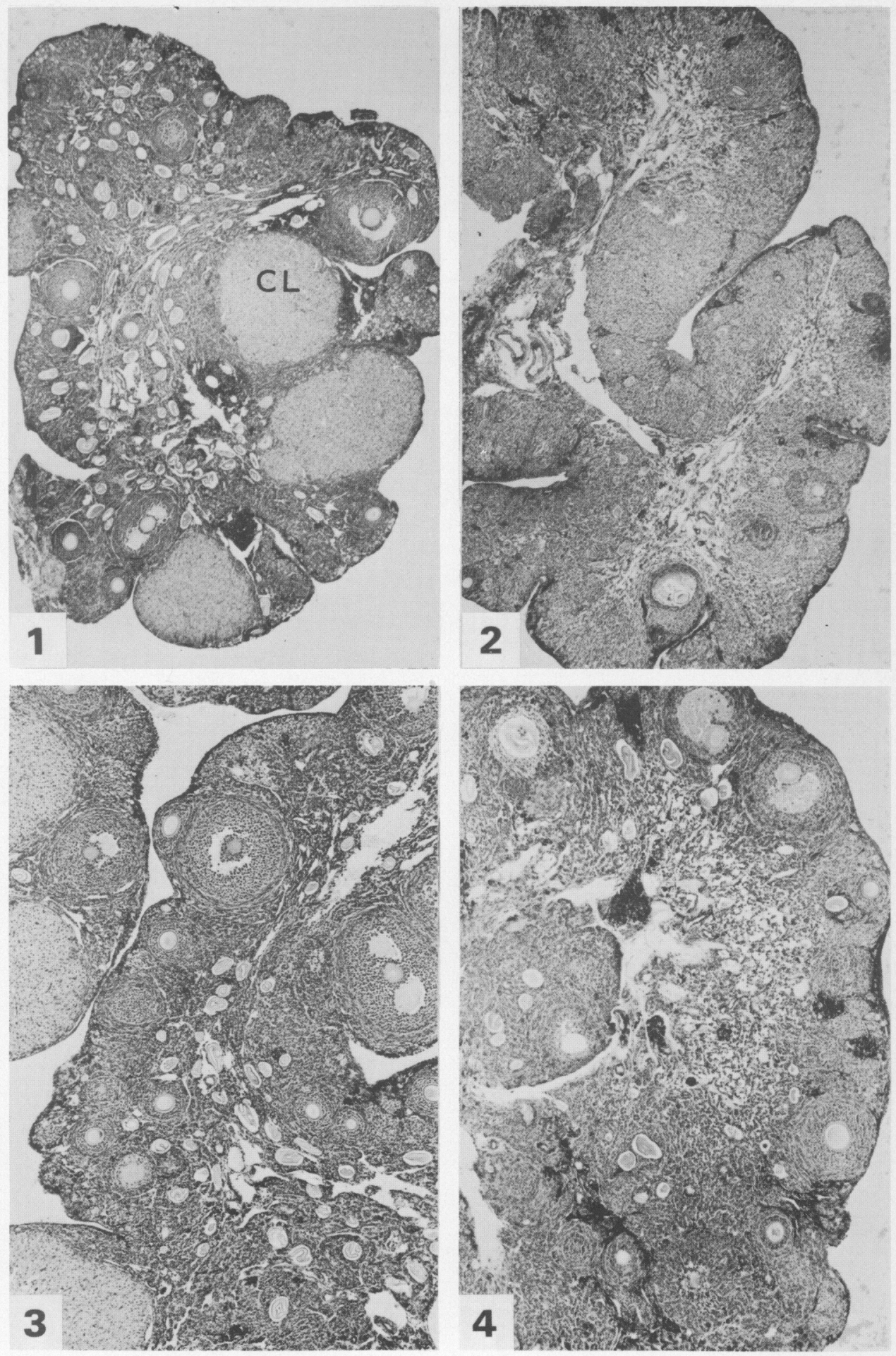

(Facing p. 40) 
elevated $(P<0.005)$ in older females, but there were no statistically significant differences between pituitary concentrations of FSH or prolactin in the young and old hamsters (Table 1).

Table 1. Mean \pm s.e.m. weights and hormone concentrations for young dioestrous and aged anoestrous hamsters (no. in parentheses)

\begin{tabular}{|c|c|c|}
\hline & \multicolumn{2}{|c|}{ Age of hamsters (months) } \\
\hline & $\begin{array}{c}3-5 \\
\text { (dioestrous) }\end{array}$ & $\begin{array}{c}13-17 \\
\text { (anoestrous) }\end{array}$ \\
\hline Body wt (g) & $128 \cdot 5 \pm 5.9(12)$ & $107 \cdot 3 \pm 4 \cdot 0(22)^{* *}$ \\
\hline $\begin{array}{l}\text { Organ wet wt }(\mathrm{mg} / 100 \mathrm{~g} \text { bod } \\
\text { Pituitary } \\
\text { Ovary }\end{array}$ & $\begin{array}{r}4.4 \pm 0.3(12) \\
11.5 \pm 0.5(12)\end{array}$ & $\begin{array}{c}5 \cdot 2 \pm 0 \cdot 3(22) \\
19 \cdot 3 \pm 1 \cdot 2(22)^{*}\end{array}$ \\
\hline $\begin{array}{l}\text { Hormones } \\
\text { Plasma } \\
\text { Progesterone }(\mathrm{ng} / \mathrm{ml}) \\
\text { Oestradiol-17 } \beta(\mathrm{pg} / \mathrm{ml}) \\
\text { LH }(\mathrm{ng} / \mathrm{ml}) \\
\text { FSH }(\mathrm{ng} / \mathrm{ml}) \\
\text { Prolactin }(\mathrm{ng} / \mathrm{ml})\end{array}$ & $\begin{array}{c}19.7 \pm 2.6(8) \\
132.2 \pm 17.7(8) \\
4.8 \pm 0.7(12) \\
328.9 \pm 24.5(12) \\
13.5 \pm 0.9(12)\end{array}$ & $\begin{aligned} & 5.6 \pm 0.7(18)^{* *} \\
& 69.5 \pm 10.8(19)^{*} \\
& 16.3 \pm 1.4(21)^{* *} \\
& 521.6 \pm 21.1(21)^{* *} \pm 2 \\
& 6.6 \pm 0.7(22)^{* *}\end{aligned}$ \\
\hline $\begin{array}{l}\text { Pituitary } \\
\text { LH (ng/ } / \mu \mathrm{g}) \\
\text { FSH }(\mathrm{ng} / \mu \mathrm{g}) \\
\text { Prolactin }(\mathrm{ng} / \mu \mathrm{g})\end{array}$ & $\begin{array}{r}1 \cdot 1 \pm 0.1(12) \\
12 \cdot 6 \pm 1.2(12) \\
48.6 \pm 6 \cdot 0(12)\end{array}$ & $\begin{array}{l}1 \cdot 6 \pm 0 \cdot 1(11)^{*} \\
17 \cdot 4 \pm 2 \cdot 5(11) \\
34 \cdot 0 \pm 4 \cdot 0(11)\end{array}$ \\
\hline
\end{tabular}

Statistically significantly different from values for $3-5$-month-old hamsters: ${ }^{*} P<0.005$, ** $P<0.001$ (Student's $t$ test).

There were more follicles in which an antrum was forming (type 5) and fewer follicles with a prominent antrum (type 6) in anoestrous hamsters (Table 2). Many of the antral follicles in anoestrous hamsters were atretic and not included in Table 2. Approximately the same number of preantral follicles (types 1-4) were found in the ovaries of both age groups, although the larger size of the ovary from anoestrous hamsters gave the impression, particularly in some sections, that fewer follicles were present in these ovaries (PI. 1, Figs 1 and 2). There were no corpora lutea in the ovaries of any aged anoestrous hamsters (compare Pl. 1, Figs 1 and 3 with Figs 2 and 4).

Table 2. Mean \pm s.e.m. numbers of oocytes of normal appearance and their stage of follicular development in individual ovaries from 10 young dioestrous and 10 aged anoestrous hamsters

\begin{tabular}{ccc}
\hline & \multicolumn{2}{c}{ Age of hamsters (months) } \\
\cline { 2 - 3 } Type of follicles $\dagger$ & $\begin{array}{c}3-5 \\
\text { (dioestrous) }\end{array}$ & $\begin{array}{c}13-17 \\
\text { (anoestrous) }\end{array}$ \\
\hline 1 & $185 \cdot 3 \pm 20 \cdot 0$ & $173 \cdot 2 \pm 25 \cdot 3$ \\
2 & $35.8 \pm 1.9$ & $29.9 \pm 4.4$ \\
3 & $11.1 \pm 2 \cdot 0$ & $8.4 \pm 1 \cdot 2$ \\
4 & 0 & 0 \\
5 & $2.2 \pm 1.5$ & $6.3 \pm 1 \cdot 2^{*}$ \\
6 & $7.1 \pm 2.3$ & $1.7 \pm 1 \cdot 2^{* *}$ \\
\hline
\end{tabular}

† Classification according to Greenwald (1974).

Statistically significantly different from value for 3-5month-old hamsters: ${ }^{*} P<0.01,{ }^{* *} P<0.001$ (Student's $t$ test). 


\section{Study 2}

At the onset of the study, mean ( \pm s.e.m.) body weights of the anoestrous hamsters $(117.6 \pm$ $3.3 \mathrm{~g})$ were less $(P<0.001$ and $P<0.01)$ than those of young $(158.8 \pm 5.9 \mathrm{~g})$ or aged $(131.5$ $\pm 3.0 \mathrm{~g}$ ) hamsters that were still exhibiting cycles. After 5 months the mean body weights of the remaining hamsters were $113.8 \pm 1.9 \mathrm{~g}$ (anoestrous), $164.9 \pm 4.9 \mathrm{~g}$ (young cyclic) and $131.3 \pm$ $7.1 \mathrm{~g}$ (aged cyclic). Therefore, it did not appear as if the bleedings had an adverse effect on the body weight of the animals.
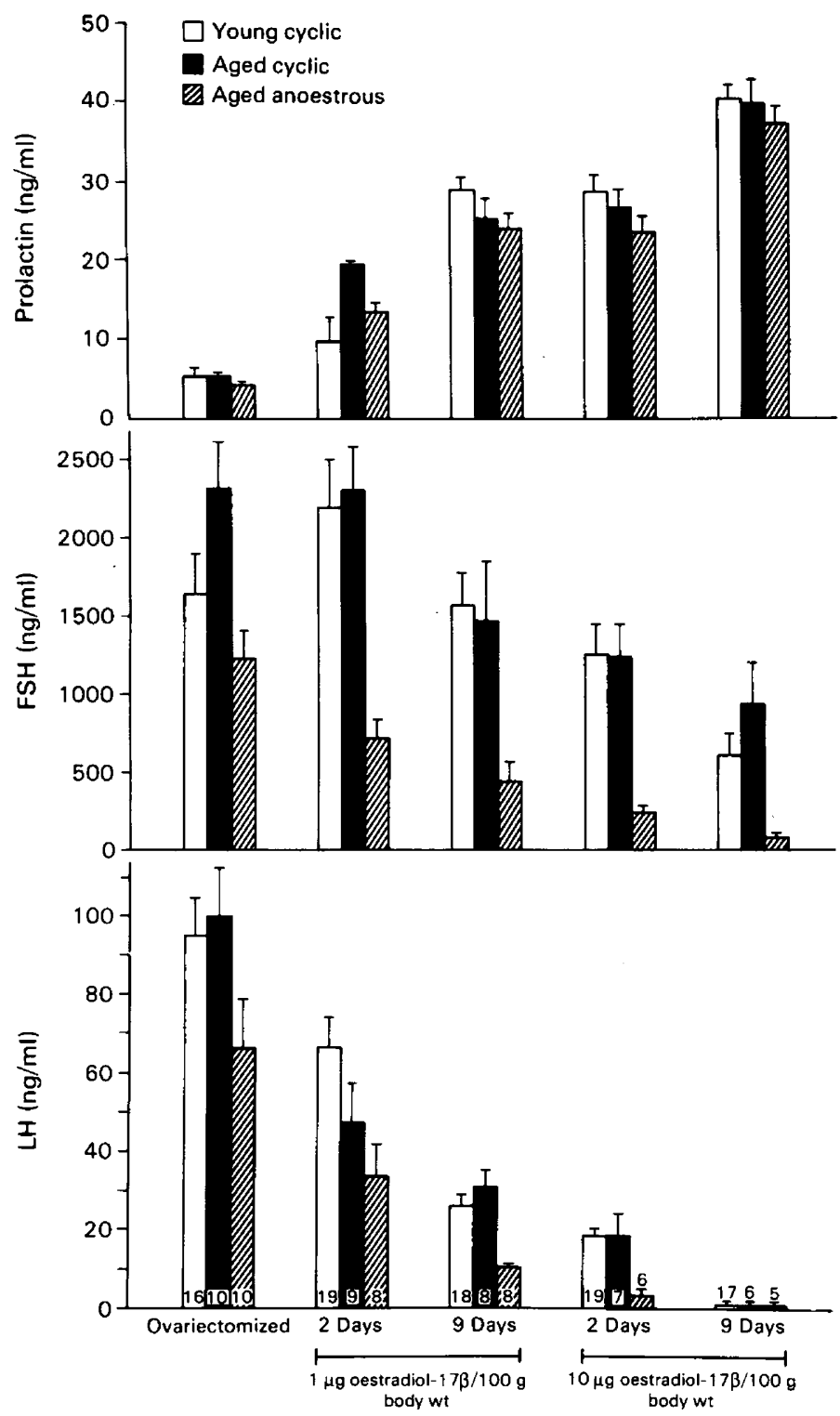

Text-fig. 1. Plasma concentrations of LH, FSH and prolactin in young and aged cyclic and aged anoestrous golden hamsters after ovariectomy and treatments with oestradiol-17 $\beta$. Blood was acquired by cardiac puncture from the same animals throughout the study by allowing 3-4 weeks for recovery between experiments. Values are mean \pm s.e.m. for the no. of animals indicated. 
All three groups of hamsters showed markedly higher concentrations of gonadotrophins 3 weeks after ovariectomy when compared to those in intact animals. The anterior pituitary gland of aged anoestrous hamsters, however, was incapable of responding to the same degree as that of cyclic hamsters because LH and FSH concentrations were considerably lower in the former group (Text-fig. 1). Prolactin concentrations were similar in young and aged cyclic females and aged anoestrous animals. When the same ovariectomized hamsters were treated with various concentrations of oestradiol-17 $\beta$ for different periods, the numbers of animals from which blood was collected were not consistent from experiment to experiment (Text-fig. 1). This occurred because of the death of some of the animals and because of difficulties encountered in obtaining blood by cardiac puncture. None of the aged hamsters died immediately following bleeding and all appeared to be physiologically normal $24 \mathrm{~h}$ after obtaining blood. The experience, however, did appear to be more traumatic for the older animals and 4 aged cycling and 5 aged anoestrous females died at other times between bleedings. Whether these deaths resulted from natural causes or from the bleeding routine is not known. Two-way analysis of variance was chosen to evaluate the data throughout the entire set of experiments. For these statistics only hamsters from which blood had been collected after each of the 4 treatments of exogenous oestradiol-17 $\beta$ were applicable (young cyclic, $\mathrm{N}=12$; aged cyclic, $\mathrm{N}=6$; aged anoestrous, $\mathrm{N}=5$ ). After treatment with oestradiol-17 $\beta$ there was a progressive decline in LH and FSH $(P<0.001)$ and a progressive rise in prolactin $(P<0.001)$ concentrations in plasma in all 3 groups of hamsters, depending upon the concentration and the length of time of oestrogen administration. The age by treatment interaction, however, indicated that the pattern of gonadotrophin decline (LH, $P<$ 0.001 ; FSH, $P<0.01)$ and prolactin increase $(P<0.01)$ was not parallel for the three groups of hamsters. Changes for aged anoestrous hamsters differed from those of both other groups, largely because the decline in LH levels from 2 to 9 days $(10 \mu$ g oestradiol-17ß) was greater for cyclic animals. Aged anoestrous hamsters receiving $1 \mu \mathrm{g}$ oestradiol-17 $\beta$ for 2 days experienced a greater drop in FSH concentrations than did either group of cyclic hamsters when comparing these values with those obtained before oestradiol-17 $\beta$ treatment. Prolactin values were not parallel in the 3 groups, primarily because of the higher prolactin concentrations in aged cyclic hamsters receiving $1 \mu \mathrm{g}$ oestradiol- $17 \beta$ for 2 days.

\section{Discussion}

Hamsters lose some body weight (approximately 15-20 g) upon entering an anoestrous state. This was the primary reason for waiting a month or more before taking blood samples, thus permitting the animals' weight to stabilize. The loss of body weight in aged anoestrous hamsters may result from changes in the appetite centre of the hypothalamus. Dampening of the appetite may also result from sustained high levels of gonadotrophins, because rats are known to consume less food during the evening of oestrus (Kennedy, 1966). Another indication that the hypothalamus may be impaired stems from a very small number of anoestrous hamsters (beyond 18 months of age) entering hibernation. This phenomenon, which has taken place under normal room temperature $\left(21-23^{\circ} \mathrm{C}\right)$, has only been observed in the aged anoestrous females (unpublished data). Occasionally an older hamster becomes anoestrous because of illness; however, none of the females used in these studies was considered to be in poor health. No gross pathological lesions were observed in any of the anoestrous hamsters used in these studies and the general appearances of the various internal organs were similar to those of aged cyclic animals.

The histological appearance of ovaries taken from anoestrous hamsters indicated that there were few well-developed antral follicles. Most of the follicles which had formed an antrum were in various stages of atresia. In the cyclic hamster, on the morning following ovulation, the number of larger follicles that will develop for the next ovulation has already been determined 
(Greenwald, 1961), presumably because the preovulatory surge of gonadotrophins recruits the next set of follicles (Greenwald, 1974). By the day of dioestrus the number of antral follicles per ovary generally coincides with the number of ova released at the time of ovulation (Greenwald, $1961,1974)$. The number of antral follicles in ovaries from younger hamsters in the present study agrees with previous data (Greenwald, 1974). In cyclic hamsters, between dioestrus and pro-oestrus, most follicles smaller than $392 \mu \mathrm{m}$ in diameter are eliminated by atresia (Greenwald, 1961). If gonadotrophin levels in anoestrous hamsters vary at other times of the day, perhaps the fluctuation is sufficient to trigger the development of a new set of follicles before the previous set has had an opportunity to complete their development. This theory is supported by the morphological similarities of ovaries from anoestrous hamsters and those from hamsters maintained under a short photoperiod (Tyler \& Campbell, 1980). Turek \& Campbell (1979) have suggested that the cause of acyclicity in hamsters exposed to short periods of light $(5 \mathrm{~h}$ light:18 $\mathrm{h}$ dark) results from large daily diurnal fluctuations in serum gonadotrophins which would normally occur in the hamster only on the day of ovulation.

Plasma concentrations of hormones associated with the reproductive system of the anoestrous hamster vary considerably from those of similarly aged females exhibiting a normal oestrous cycle (Blaha \& Leavitt, 1974; Parkening et al., 1978). It is assumed that these differences are a reflection of changes within the hypothalamic-hypophysial-ovarian complex and are not the result of differences in clearance rates of these hormones. Anoestrous hamsters have significantly higher plasma gonadotrophin levels than do anoestrous rats, which have decreased LH levels and similar FSH levels compared to those in younger dioestrous rats with normal cycles (Huang et al., 1978). Plasma concentrations of prolactin, however, are significantly lower in anoestrous hamsters, but higher in anoestrous rats (Huang et al., 1976; Riegle \& Miller, 1978; Meites et al., 1978) when comparing concentrations from these animals with levels found in younger dioestrous females of the same species. In contrast, the depressed levels of progesterone and oestradiol-17 $\beta$ in anoestrous hamsters are similar to findings for anoestrous rats (Huang et al., 1978). The anoestrous state of the aged rat has been attributed to tumorous pituitaries (Meites et al., 1978). It is doubtful that this is the cause of the anoestrous condition in ageing hamsters because none of the pituitaries appeared grossly abnormal and pituitary prolactin concentrations were not different from those of younger hamsters.

The diminished levels of gonadotrophins found in aged anoestrous ovariectomized hamsters when compared with similarly treated cyclic hamsters agrees with data reported for older ovariectomized rats which had exhibited either constant oestrus or repetitive pseudopregnancy before ovariectomy (Howland \& Preiss, 1975; McPherson, Costoff \& Mahesh, 1977; Wise \& Ratner, 1980). The reason that aged anoestrous hamsters fail to respond in the same way as aged cyclic hamsters to a loss of negative feedback is not known, although it has been speculated that in aged constant-oestrous rats the major defect resides within the hypothalamus, whereas in aged repetitive pseudopregnant rats the major problem is decreased pituitary responsiveness (Wise \& Ratner, 1980). Studies conducted on aged anoestrous hamsters to determine GnRH levels or the response of their pituitary-hypothalamic complex to exogenous GnRH would be beneficial in determining how the complex is functioning in relation to age in this species.

The pattern of hormonal secretion in the anoestrous hamster appears to coincide with that reported for the post-menopausal woman. Serum levels of progesterone, oestradiol-17 $\beta$ and prolactin become significantly lower, while levels of LH and FSH become significantly higher in post-menopausal women as compared with levels found in premenopausal women (Sherman, West \& Korenman, 1976; Scaglia et al., 1976; Reyes, Winter \& Faiman, 1977).

Since ageing rats have a tendency to enter periods of constant oestrus or repetitive pseudopregnancies and do not normally become anoestrous until relatively late in life, the anoestrous hamster may prove to be useful for studying the effects of ageing on the reproductive system for comparison with man. A similar conclusion was also reached from recent studies using C57BL/6 mice (Parkening et al., 1980a). The major advantage of conducting ageing 
studies with the hamster, however, is that a sufficient amount of plasma can be obtained from a single female to assay for steroids, gonadotrophins and prolactin. Although additional studies will have to be conducted to determine the causes responsible for some aged hamsters becoming anoestrous, from the present data it is suggested that age-related changes occurring primarily within the hypothalamus are responsible for the weight loss in the anoestrous animal, the morphology of their ovaries and the diminished response of their pituitary to secrete gonadotrophins following ovariectomy.

This research was supported in part by NIH Grant No. AG-00757 awarded to T.A.P. We thank the NIAMDD and Dr A. F. Parlow for providing materials for the radioimmunoassay of LH, FSH and prolactin.

\section{References}

Aschheim, P. (1961) La pseudogestation à répétition chez les rattes séniles. C.r. hebd. Séanc. Acad. Sci., Paris D 253, 1988-1990.

Aschheim, P. (1976) Aging in the hypothalamichypophyseal ovarian axis in the rat. In Hypothalamus, Pituitary and Aging, pp. 376-418. Eds A. V. Everitt \& J. A. Burgess. Charles C. Thomas, Springfield.

Bast, J.D. \& Greenwald, G.S. (1974) Serum profiles of follicle-stimulating hormone, luteinizing hormone and prolactin during the estrous cycle of the hamster. Endocrinology 94, 1295-1299.

Bex, F.J. \& Goldman, B.D. (1975) Serum gonadotropins and follicular development in the Syrian hamster. Endocrinology 96, 928-933.

Blaha, G.C. \& Leavitt, W.W. (1974) Ovarian steroid dehydrogenase histochemistry and circulating progesterone in aged golden hamsters during the estrous cycle and pregnancy. Biol. Reprod. 11, 153-161.

Clemens, J.A. \& Meites, J. (1971) Neuroendocrine status of old constant estrous rats. Neuroendocrinology 7 , 249-256.

Greenwald, G.S. (1961) Quantitative study of follicular development in the ovary of the intact or unilaterally ovariectomized hamster. J. Reprod. Fert. 2, 351-361.

Greenwald, G.S. (1974) Quantitative aspects of follicular development in the untreated and PMS-treated cyclic hamster. Anat. Rec. 178, 139-144.

Howland, B.E. \& Preiss, C. (1975) Effects of aging on basal levels of serum gonadotropins, ovarian compensatory hypertrophy, and hypersecretion of gonadotropins after ovariectomy in female rats. Fert. Steril. 26, 271-276.

Huang, H. H. \& Meites, J. (1975) Reproductive capacity of aging female rats. Neuroendocrinology 17, 289295.

Huang, H.H., Marshall, S. \& Meites, J. (1976) Capacity of old versus young female rats to secrete LH, FSH and prolactin. Biol. Reprod. 14, 538-543.

Huang, H.H., Steger, R.W., Bruni, J.F. \& Meites, J. (1978) Patterns of sex steroid and gonadotropin secretion in aging female rats. Endocrinology 103, 1855-1859.

Kennedy, G.C. (1966) Food intake, energy balance and growth. Br. med. Bull. 22, 216-220.

Lu, K.H., Hopper, B.R., Vargo, T.M. \& Yen, S.S.C.
(1979) Chronological changes in sex steroid, gonadotropin and prolactin secretion in aging female rats displaying different reproductive states. Biol. Reprod. 21, 193-203.

McPherson, J.C., Costoff, A. \& Mahesh, V.B. (1977) Effects of aging on the hypothalamic-hypophysealgonadal axis in female rats. Fert. Steril. 28, 13651370.

Meites, J., Huang, H.H. \& Simpkins, J.W. (1978) Recent studies on neuroendocrine control of reproductive senescence in rats. In Aging, Vol. 4, The Aging Reproductive System, pp. 213-235. Ed. E. L. Schneider. Raven Press, New York.

Orczyk, G.P., Caldwell, B.V. \& Behrman, H.R. (1974) Estrogens, estradiol, estrone and estriol. In Methods of Hormone Radioimmunoassay, pp. 333-345. Eds B. M. Jaffe \& H. R. Behrman. Academic Press, New York.

Parkening, T.A., Saksena, S.K. \& Lau, I.F. (1978) Postovulatory levels of progestogens, oestrogens, luteinizing hormone and follicle-stimulating hormone in the plasma of aged golden hamsters exhibiting a delay in fertilization. $J$. Endocr. 78, 147-148.

Parkening, T.A., Collins, TJ. \& Smith, E.R. (1980a) Plasma and pituitary concentrations of LH, FSH and prolactin in aged female C57BL/6 mice. J. Reprod. Fert. 58, 377-386.

Parkening, T.A., Collins, T.J. \& Smith, E.R. (1980b) A comparative study of prolactin levels in five species of aged female laboratory rodents. Biol. Reprod. 22, 513-518.

Reyes, F.I., Winter, J.S.D. \& Faiman, C. (1977) Pituitary-ovarian relationships preceding the menopause. I. A cross-sectional study of serum follicle-stimulating hormone, luteinizing hormone, prolactin, estradiol, and progesterone levels. $A m$. J. Obstet. Gynec. 129, 557-564.

Riegle, G.D. \& Miller, A.E. (1978) Aging effects on the hypothalamic-hypophyseal gonadal control system in the rat. In Aging, Vol. 4, The Aging Reproductive System, pp. 159-192. Ed. E. L. Schneider. Raven Press, New York.

Saksena, S.K., Lau, I.F. \& Chang, M.C. (1976) The inhibition of the conversion of testosterone into $5 \alpha$-dihydrotestosterone in the reproductive organs of the male rat. Steroids 27, 751-757. 
Saksena, S.K., Lau, I.F. \& Chang, M.C. (1977) Determination of seven unconjugated steroids in the blood and seminal plasma of the fertile male rabbit. Horm. Res. 8, 117-124.

Scaglia, H., Medina, M., Pinto-Ferreira, A.L., Vázques, G., Gual, C. \& Peréz-Palacios, G. (1976) Pituitary $\mathrm{LH}$ and FSH secretion and responsiveness in women of old age. Acta endocr., Copenh. 81, 673-679.

Sherman, B.M., West, J.H. \& Korenman, S.G. (1976) The menopausal transition: analysis of $\mathrm{LH}, \mathrm{FSH}$, estradiol, and progesterone concentrations during menstrual cycles of older women. J. clin. Endocr. Metab. 42, 629-636.

Thung, P.J., Boot, L.M. \& Mühbock, O. (1956) Senile changes in the oestrous cycle and in ovarian structure in some inbred strains of mice. Acta endocr., Copenh. 23, 8-32.

Turek, F.W. \& Campbell, C.S. (1979) Photoperiodic regulation of neuroendocrine-gonadal activity. Biol. Reprod. 20, 32-50.

Tyler, J.L. \& Campbell, C.S. (1980) Hormonal and ovarian correlates of photic-induced recovery of cyclicity in anestrous hamsters. Biol. Reprod., Suppl. 1, 83A, Abstr.

Wise, P.M. \& Ratner, A. (1980) Effect of ovariectomy on plasma LH, FSH, estradiol, and progesterone and medial basal hypothalamic LHRH concentrations in old and young rats. Neuroendocrinology 30, 15-19.

Received 21 January 1981 